\title{
Glucocorticoids and Type 2 Diabetes: From Physiology to Pathology
}

\section{Guido Di Dalmazi, Uberto Pagotto, Renato Pasquali, and Valentina Vicennati}

Division of Endocrinology, Department of Medical and Surgical Science, S. Orsola-Malpighi Hospital, University Alma Mater Studiorum, Via Massarenti 9, 40138 Bologna, Italy

Correspondence should be addressed to Valentina Vicennati, vicennati@aosp.bo.it

Received 10 August 2012; Accepted 26 November 2012

Academic Editor: Peter M. Clifton

Copyright ( $\odot 2012$ Guido Di Dalmazi et al. This is an open access article distributed under the Creative Commons Attribution License, which permits unrestricted use, distribution, and reproduction in any medium, provided the original work is properly cited.

\begin{abstract}
Type 2 diabetes mellitus is the result of interaction between genetic and environmental factors, leading to heterogeneous and progressive pancreatic $\beta$-cell dysfunction. Overweight and obesity are major contributors to the development of insulin resistance and impaired glucose tolerance. The inability of $\beta$ cells to secrete enough insulin produces type 2 diabetes. Abnormalities in other hormones such as reduced secretion of the incretin glucagon-like peptide 1 (GLP-1), hyperglucagonemia, and raised concentrations of other counterregulatory hormones also contribute to insulin resistance, reduced insulin secretion, and hyperglycaemia in type 2 diabetes. Clinical-overt and experimental cortisol excess is associated with profound metabolic disturbances of intermediate metabolism resulting in abdominal obesity, insulin resistance, and low HDL-cholesterol levels, which can lead to diabetes. It was therefore suggested that subtle abnormalities in cortisol secretion and action are one of the missing links between insulin resistance and other features of the metabolic syndrome. The aim of this paper is to address the role of glucocorticoids on glucose homeostasis and to explain the relationship between hypercortisolism and type 2 diabetes.
\end{abstract}

\section{Introduction}

Type 2 diabetes mellitus is a complex endocrine and metabolic disorder. The interaction between several genetic and environmental factors results in a heterogeneous and progressive disorder with variable degrees of insulin resistance and pancreatic $\beta$-cell dysfunction [1]. Overweight and obesity are major contributors to the development of insulin resistance and impaired glucose tolerance; when $\beta$-cells are no longer able to secrete enough insulin to overcome insulin resistance, impaired glucose tolerance progresses to type 2 diabetes [2,3]. Abnormalities in other hormones such as reduced secretion of the incretin glucagon-like peptide 1 (GLP-1), hyperglucagonaemia, and raised concentrations of other counter-regulatory hormones also contribute to insulin resistance, reduced insulin secretion, and hyperglycaemia in type 2 diabetes [4-7]. Clinical-overt [8] and experimental [9] cortisol excess is associated with increased blood pressure and profound metabolic disturbances of intermediate metabolism resulting in abdominal obesity, insulin resistance, and low HDL-cholesterol levels, which can lead to diabetes. Therefore it has been suggested that subtle abnormalities in cortisol secretion and action are one of the missing links between insulin resistance and other features of the metabolic syndrome $[10,11]$. The aim of this paper is to address the role of glucocorticoids on glucose homeostasis and to explain the relationships between hypercortisolism and diabetes.

\section{Glucocorticoids and Glucose Metabolism}

Glucocorticoid hormones are produced by the adrenal cortex under control of the hypothalamic-pituitary-adrenal (HPA) axis. They exert their function in different target tissues by binding two intracellular receptors: the glucocorticoid receptor and the mineralcorticoid receptor [12]. It is well known that the effects of glucocorticoids have a great variability between subjects, because of the different receptor sensitivity which is mostly genetically determined [13, 14]. Many other factors contribute to modulate the biological effects 
of glucocorticoids in target tissues; among them, the $11 \beta$ hydroxysteroid dehydrogenase (11 $\beta$-HSD) enzymes, which interconvert cortisol to its inactive metabolite cortisone, are of particular interest: $11 \beta$-HSD type $1(11 \beta$-HSD 1$)$ is mainly expressed in the liver and in the adipose tissue and amplifies local glucocorticoid action converting cortisone to cortisol, whereas $11 \beta$-HSD type $2(11 \beta$-HSD2) is mainly expressed in the kidney and reduces glucocorticoid-induced effects by converting cortisol to the inactive cortisone [15] (see specific paragraph below).

\section{Hypercortisolism and Diabetes}

3.1. Endogenous Hypercortisolism (EH): Cushing's Syndrome/Disease. Cushing's syndrome (CS) is a clinical condition resulting from chronic exposure to glucocorticoid excess. $\mathrm{EH}$ can be either adrenocorticotropin hormone (ACTH) dependent (mostly due to pituitary adenomas, known as Cushing disease, CD) or ACTH independent (due to adrenal adenomas or hyperplasia) known as CS. Cortisol excess leads to a clinical phenotype that harbours all components of the metabolic syndrome as well as muscle weakness, hirsutism, increased bruisability, and psychological dysfunction [16-26]. Hypercortisolism is responsible for the occurrence of chronic metabolic complications, such as insulin resistance, diabetes mellitus, dyslipidemia, cardiovascular disease, and bone fragility [27], independently of the presence of obesity.

Diabetes is considered to be a common complication of chronic exposure to glucocorticoid excess, and it is an important contributing factor to the morbidity and the mortality of the patients with EH [28]. The overall mortality in EH doubles the general population: in this clinical setting, diabetes, hypertension, and uncontrolled hypercortisolism have been shown to be important predictors of overall mortality [29-31]. Most of the deaths occur in patients with persistent hypercortisolism; moreover, patients who achieve the remission of the disease after many years of hypercortisolism have, however, a high risk of death [28].

3.2. Incidence of EH. It is widely accepted that CS is an uncommon disorder; however, its diagnosis is often delayed because of the difficulties in recognizing the clinical signs specific to this condition. In a Danish study, an incidence of two cases per one million persons per year was found [32], while a Spanish study showed an incidence of 2.5 cases per one million persons per year [29]. A recent large-scale retrospective survey carried out in New Zealand by Bolland showed that the prevalence of all forms of CS (the majority of these cases were of pituitary origin) was 79 cases per million, and the incidence was 1.8 per million per year [33].

3.3. Pathophysiology of Diabetes in EH. Insulin is produced and secreted by the pancreatic $\beta$-cells, which play a crucial role in the maintenance of glucose homeostasis; insulin secretion is stimulated by an increase in blood glucose levels and is modulated by hormonal and neuronal stimuli. The main intracellular signals in insulin secretion are ATP,
$\mathrm{Ca}^{2+}$, cAMP, and phospholipid-derived signals. When blood glucose increases, it is transported into the $\beta$-cell by glucose transporters. Glucose metabolism increases ATP production in $\beta$-cell mitochondria, and the increase in the intracellular concentration of ATP closes the ATP-sensitive $\mathrm{K}^{+}$channels. This causes depolarization of the $\beta$-cell membrane, opening voltage-dependent calcium channels, leading to intracellular $\mathrm{Ca}^{2+}$ influx. The rise in $\mathrm{Ca}^{2+}$ stimulates the exocytosis of insulin vesicles. Insulin secretion by the $\beta$ cell is greater when glucose is administered orally than with intravenous administration. This effect is triggered by the action of gastrointestinal hormones named incretins, such as glucagon-like peptide 1 (GLP-1) and glucose-dependent insulinotropic polypeptide, which act on insulin secretion by increasing cAMP levels in the $\beta$-cell. Insulin is secreted in a biphasic fashion: exposure of $\beta$-cell to an abrupt increase in glucose leads to insulin secretory-vesicle discharge. These insulin-filled vesicles are immediately available for exocytosis (first phase). The second phase is provided by granules of insulin mobilized from an intracellular pool.

Glucocorticoids were shown to cause various degrees of $\beta$-cell dysfunction, reducing insulin sensitivity and impairing $\beta$-cell function [34], by acting through glucocorticoid receptors which are also expressed on pancreatic $\beta$-cells. Glucocorticoids may also impair the uptake and the metabolism of glucose in $\beta$-cells through genomic actions (i.e., modulation of gene expression by nuclear glucocorticoid receptor) which lead to a decrease in the efficacy of cytoplasmic $\mathrm{Ca}^{2+}$ on the exocytotic process of insulin secretory vehicles [35]. It was also recently reported that short-term exposure to glucocorticoids reduced the insulinotropic effects of GLP-1 [36]. The most important metabolic consequences of glucocorticoid excess occur during the postprandial period when these hormones exert anti-insulin effects in liver, skeletal muscle, and adipose tissue. Insulin favours the uptake and storage of glucose as glycogen in muscle and fat and reduces lipolysis by the inhibition of fatty acid release into the blood; insulin also inhibits hepatic gluconeogenesis and glycogenolysis. Glucocorticoid excess may affect all these biological activities leading to the development of insulin resistance. Moreover, glucocorticoids induce a postreceptor defect by decreasing key mediators of insulin action in peripheral tissues (insulin receptor substrate-1, phosphatidylinositol3 kinase, and protein kinase B) [37]. These actions cause impaired glucose transporter translocation to the cell surface leading to a decrease in glucose uptake. The effects of glucocorticoid excess on hepatic gluconeogenesis have been also shown during fasting, as suggested by in vitro studies demonstrating a dexamethasone-induced activation of key enzymes involved in gluconeogenesis, such as phosphoenolpyruvate carboxykinase [38]. This effect may involve other proteins, such as liver $\mathrm{X}$ receptors, providing evidence for crosstalk between different metabolic pathways, such as glucose and cholesterol pathways, which could be affected by glucocorticoid excess [39]. Glucocorticoids exert their negative effects on insulin sensitivity also by modifying lipid and protein metabolism: they stimulate proteolysis, increasing aminoacid concentration which impairs different 
steps of insulin signalling, and increasing lipolysis which cause the elevation of free fatty acids that contribute to the impairment of glucose uptake and disposal [40]. Insulin resistance is also favoured by the abnormal distribution of body fat mass occurring in patients with CS, characterized by a specific increase of visceral adipose tissue. Finally, glucocorticoids may modulate the expression and the activity of adipokines, such as adiponectin, leptin, and apelin, which in turn may impair insulin sensitivity [41].

3.4. Incidence of Diabetes in EH and Diagnostic Tools. About half of CS patients have been shown to have alterations of glucose metabolism, and two thirds of these cases had diabetes, regardless of gender [42]. Diabetes occurs independently of the aetiology of glucocorticoid excess and does not seem to be correlated to disease duration. The close association between glucocorticoid excess and abnormalities in glucose metabolism is also demonstrated by the high unexpected prevalence of endogenous CS (up to $9 \%$ ) in patients with diabetes mellitus, with difficult control of the disease and with coexistence of other features of glucocorticoid excess, such as central obesity and purple striae [43].

However, the available data do not support the screening for CS in diabetes clinics because of the high costeffectiveness and the lack of specific tests for diagnosing CS, especially in patients with slightly elevated cortisol secretion and subclinical hypercortisolism [44]. Special consideration should be given to subclinical cortisol secretion in adrenal incidentalomas (see specific paragraph below).

In patients with $\mathrm{EH}$ the measurement of fasting glucose may underestimate the real prevalence of glucose disorders, as suggested by the observation that more than one half of patients with $\mathrm{EH}$ and diabetes were shown to have normal fasting glucose [27]. This seems to be true also for patients taking exogenous glucocorticoids, in whom high glycemic values were shown to occur in the afternoon and in the evening [45]. The oral glucose tolerance test (OGTT) is therefore considered the diagnostic gold standard for identifying the impairment of glucose metabolism in $\mathrm{EH}$ [46], and for monitoring changes in glucose homeostasis. Measurement of glycated haemoglobin has been suggested for the diagnosis of diabetes in the general population and may be even more helpful in the clinical setting of $\mathrm{EH}$ because this parameter is an integrated measure of glucose homeostasis [47]. However, the use of glycated haemoglobin $\geq 6.5 \%$ for the diagnosis of diabetes is not yet of common practice because of problems in measuring this parameter and in interpreting the results in specific clinical conditions. Moreover, a high variability has been demonstrated in different ethnic groups in the sensitivity and specificity of glycated haemoglobin assays. Surrogate markers of peripheral insulin activity, such as homeostasis model assessment and whole-body insulin sensitivity indexes, could also be useful for the early identification of patients with insulin resistance before the development of overt diabetes [48].
3.5. Exogenous Hypercortisolism (ExH). To date, the most frequent cause of hypercortisolism is the chronic therapy with glucocorticoids mainly prescribed for their antiinflammatory effects through multiple pathways that promote the synthesis of anti-inflammatory proteins [49].

In addition to formulations intended to have systemic effects, topic formulations are widely used for specific clinical conditions and could also have systemic effects: intra-articular injections for arthritis, epidural injections for lumbar disk pain, eye drops for uveitis, nasal sprays for allergic rhinitis, inhalers for asthma, and topical ointments and creams for dermatological diseases.

In glucocorticoid-treated patients, the odds ratio for development of new-onset diabetes mellitus has been reported to be from 1.36 to 2.31 [50]; however, the exact prevalence of diabetes in these patients has been reported only in few studies, showing that glucocorticoid-induced hyperglycaemia or diabetes is a common feature:

(i) nearly $9 \%$ of patients with rheumatoid arthritis have been shown to develop diabetes 2 years after starting glucocorticoid treatment [51];

(ii) $42 \%$ of nondiabetic patients with primary renal disease treated with prednisolone $0.75 \mathrm{mg} / \mathrm{kg} /$ day were found to have 2-hour post-lunch plasma glucose concentrations higher than $200 \mathrm{mg} / \mathrm{dL}$ but normal fasting glucose levels [52]. The authors also reported that more than $50 \%$ of patients developed diabetes or impaired glucose tolerance 10 weeks after starting the treatment with prednisone (mean dose $10 \mathrm{mg} /$ day); however, one of the limits of this study was the small number of patients;

(iii) in a case-control study, the odds ratio (OR) of starting an oral hypoglycaemic agent or insulin in patients receiving a hydrocortisone-equivalent dose of 1 to $39 \mathrm{mg} /$ day was 1.77 ; patients receiving higher doses of glucocorticoids have been shown to have higher ORs: 3.02 for 40 to $79 \mathrm{mg} /$ day, 5.82 for 80 to $119 \mathrm{mg} /$ day, and 10.34 for $120 \mathrm{mg} /$ day or more [53].

Hyperglycaemia is a potential concern with both short-term (4 weeks or less) and long-term glucocorticoid treatments, such as in transplant recipients to prevent rejection or to treat graft-versus-host disease. However, there are no clear guidelines on the monitoring of blood glucose levels in patients undergoing long-term glucocorticoid treatment, and on the management of glucocorticoid-related diabetes, except for patients undergoing transplants: the international consensus guidelines published in 2003 suggest to check fasting plasma glucose level once a week for the first 4 weeks after transplantation, then at 3 and 6 months, and then once a year [54]. Though practical, this suggestion does not reflect the fact that glucocorticoids often do not affect fasting plasma glucose, especially if they are given once daily in the morning at doses of $30 \mathrm{mg}$ or less of prednisone or its equivalent. The transplant guidelines do mention that an oral glucose tolerance test may be more sensitive, but this is often cumbersome to perform. Checking random postprandial plasma glucose levels could be helpful in this regard. 
The American Diabetes Association cutoff for diagnosing diabetes when using a random (i.e., nonfasting) plasma glucose level is $200 \mathrm{mg} / \mathrm{dL}$ or higher in patients with classic symptoms of hyperglycaemia such as polyuria and polydipsia [47]. If patients have risk factors for diabetes before receiving synthetic glucocorticoids (excess weight/obesity, family history of diabetes), fasting plasma glucose level $\geq 126 \mathrm{mg} / \mathrm{dL}$ or glycated haemoglobin $\geq 6.5 \%$ might suffice to diagnose diabetes (results should be confirmed on a separate day in the absence of unequivocal hyperglycaemia).

3.6. Pathophysiology of Diabetes in ExH. Glucocorticoidinduced diabetes is similar to type 2 diabetes because glucocorticoids impair glucose metabolism mainly through increasing insulin resistance, which occurs in the liver with increased basal glucose production, and in the adipose and skeletal tissues with impaired glucose utilization: to better understand the mechanisms of glucocorticoidinduced hyperglycaemia, Pagano et al. [55] evaluated the effect of prednisolone administration for 7 days in healthy volunteers, showing $50 \%$ reduction in insulin sensitivity by using insulin clamp methods. These findings were supported by subsequent studies [56, 57]. Exogenous glucocorticoids could also interfere with the signalling pathways of various insulin secretagogues, but the exact mechanisms are still unknown. In vitro studies have been shown that glucocorticoids may reduce glucose uptake and oxidation and upregulate potassium-gated ion channels with impaired depolarization and decreased calcium influx (a stimulus for insulin granule release) [58-60]. Moreover, increased $\beta$-cell death after incubation with dexamethasone has also been shown [61].

3.7. Shared Features between Obesity, MetS, and Hypercortisolism. The metabolic syndrome (MetS) is a cluster of abnormalities that include central obesity, impaired glucose tolerance, hypertension, and dyslipidaemia [62-65]. Insulin resistance is one of the main defects which is shared between the individual components of the MetS although the strength of this correlation varies between, and even within, different populations [66].

Many studies have been shown a strong association between obesity, glucose intolerance, and diabetes: increasing body mass index (BMI) has been associated with increased incidence of impaired fasting glucose and diabetes in both sexes $[67,68]$. However, the risk of developing diabetes has been shown to be higher in females: women with BMI of 24 to $24.9 \mathrm{~kg} / \mathrm{m}^{2}$ had a risk of developing diabetes five times higher when compared to women with BMI of less than $22 \mathrm{~kg} / \mathrm{m}^{2}$; the risk of developing diabetes in women with BMI greater than $31 \mathrm{~kg} / \mathrm{m}^{2}$ and $35 \mathrm{~kg} / \mathrm{m}^{2}$ was increased up to 40 times and 93 times, respectively [69].

Both insulin levels and BMI have been shown to be independent predictors of cardiovascular disease [70]. Similar results have been found in a study performed in male health professionals: the risk of diabetes was 42 times higher with BMI greater than $35 \mathrm{~kg} / \mathrm{m}^{2}$ when compared to that of men with BMI less than $23 \mathrm{~kg} / \mathrm{m}^{2}[71,72]$. The relationship between weight gain and diabetes appears to be relatively consistent among different ethnicities [73-75].

Glucocorticoids exert their effects also in the adipose tissue influencing its activity: they promote the differentiation and proliferation of human adipocytes acting by glucocorticoid receptors which are more abundant in visceral than in subcutaneous adipose tissue [76]; glucocorticoids redistribute adiposity from peripheral to central depots, as confirmed by studies showing a positive correlation between cortisol concentrations and intra-abdominal fat; finally, they increase size and number of fat cells and activate lipolysis and release of free fatty acids into the circulation [77].

Therefore, there is evidence that cortisol could play a role in determining the adiposity in MetS, even if there are conflicting results in the literature. Increases in urinary free cortisol excretion have been reported in patients with MetS $[78,79]$, whereas other studies did not confirm this finding, showing that the urinary cortisone/cortisol ratio in women with increased abdominal fat was higher if compared to those with peripheral fat distribution, suggesting an increase in the peripheral metabolism of cortisol [80]. Furthermore, some studies showed a positive correlation between cortisol and waist circumference [81-83], whilst other authors reported no relationship between these two parameters [83, 84].

However, several studies have shown an increased responsiveness of the HPA axis to different stimuli in patients with abdominal obesity: these stimuli included food intake $[85,86]$, low-dose tetracosactide [87], and $\mathrm{CRH}$-arginine vasopressin $[88,89]$, leading to the conclusion that abdominal adiposity is associated with attenuated negative feedback in the HPA axis $[90,91]$ and with reduced diurnal variation in cortisol levels. Recently, Vicennati et al. [92] confirmed a positive relation between $24 \mathrm{~h}$ urinary free cortisol (UFC) values and waist circumference, independently of the BMI, in a cohort of overweight/obese women compared to normal weight subjects; a positive correlation between $24 \mathrm{~h}$ UFC levels and caloric intake, fat eating, and consumption of starchy foods, independently of BMI has also been shown.

3.8. 11 Beta-Hydroxysteroid Dehydrogenase Type 1 and Type 2 Diabetes. The regulation of peripheral glucocorticoid levels is critical for the maintenance of homeostasis, playing a central role in pivotal physiological processes, such as stress responses, energy metabolism, electrolyte levels, blood pressure, immunity, cell proliferation and differentiation, and cognitive functions [93].

A major determinant of glucocorticoid peripheral action seems to be the expression of the 2 isoforms of the $11 \beta$-HSD, as mentioned before. $11 \beta$-HSD1 predominantly converts low-active cortisone to the more active cortisol. This enzyme is mainly expressed in the liver and in the adipose tissue, and its expression can be induced in fibroblasts, muscles, and other tissues (934). 11 $\beta$-HSD2 converts cortisol to cortisone, and it has been found in tissues that express the mineralocorticoid receptor (especially the kidneys), allowing aldosterone to bind to this receptor [94].

Changes in the activity of these enzymes could lead to metabolic and hormonal alterations: increased $11 \beta$-HSD1 
activity in visceral adipose tissue may generate increased cortisol levels within adipose tissue and liver, promoting the development of features of the MetS [95]. Transgenic mice overexpressing $11 \beta$-HSD1 selectively in the adipose tissue have been shown to faithfully recapitulate the stigmata of the MetS [96-98], whereas $11 \beta-H S D 1-K O$ mice treated with $11 \beta$-HSD1 inhibitors have been reported to be protected from cardiometabolic risks of the obesity [99].

Therefore, it has been suggested that MetS and central obesity may result from an increased availability of glucocorticoids specifically in the liver and in the adipose tissue, and this effect has been termed "Cushing's disease of the omentum" $[100,101]$. Following this suggestion, few compounds with inhibitory activity of the $11 \beta$-HSD 1 enzymes (INCB13739, MK-0916, MK-0736) have been tested in humans [102-105]; however, the major concern about these studies is the compensatory activation of the HPA axis as a result of the decrease of cortisol production in peripheral tissues due to the inhibition of the $11 \beta$-HSD1: the chronic hyperstimulation of the adrenal glands by ACTH might result in hyperproduction of adrenal androgens (dehydroepiandrosterone, dehydroepiandrosterone-sulphate, and $\Delta 4$-androstenedione) which may lead to clinical hyperandrogenism, and mineralocorticoid precursors which may cause salt retention and arterial hypertension [106]. More longitudinal data regarding the safety profile of these compounds are needed.

3.9. Subclinical Cushing's Syndrome. Subclinical Cushing's syndrome (SCS) is defined as alterations of the hypothalamic-pituitary-adrenal (HPA) axis without the classic signs or symptoms specific to overt glucocorticoid excess [107, 108]. The clinical consequences of the long-term exposure to mild cortisol excess have yet to be defined, and the potential improvement of comorbidities after surgical treatment of SCS patients is still a matter of debate.

It is well known that alterations of the glucose metabolism may occur in the presence of an excessive cortisol production, such as in overt CS, toward the complex net of mechanisms described above; however, studies on subclinical hypercortisolism available up to now are not able to answer the question if the same mechanisms are involved in the alterations of the glucose metabolism reported in these patients, and in the development of diabetes.

The prevalence of SCS has been reported in many series of patients with adrenal masses discovered serendipitously, and it has been estimated in up to $30 \%$ of patients bearing an adrenal incidentaloma $[109,110]$. In SCS patients, previous studies reported a variable prevalence of diabetes, ranging from $5 \%$ to $50 \%$ [111]. This wide variability could be mainly explained with 2 diagnostic biases: (i) because of the definition of SCS itself, the diagnosis of this condition in patients with adrenal incidentalomas is possible only using biochemical and hormonal criteria; moreover, the available guidelines lack a clear consensus on which are the best tests that should be used to define this condition $[112,113]$, leading to a nonhomogeneity in the classification of patients. (ii) The second bias is related to the diagnosis of alterations of the glucose metabolism, defined using fasting glucose and fasting insulin in some studies $[114,115]$, and using the OGTT in others [116, 117].

In a recent cross-sectional study that we performed on 348 patients with adrenal incidentalomas [118], we defined 4 groups of subjects with progressively increased patterns of subclinical cortisol hypersecretion, ranging from nonsecreting adenomas to intermediate phenotypes of cortisol hypersecretion, and to SCS. We used the $1 \mathrm{mg}$ overnight dexamethasone suppression test as the primary criterion for the diagnosis of nonsecreting adenomas and SCS; basal ACTH and the UFC were used as adjunctive criteria to define the intermediate minor and intermediate major phenotypes. Diabetes was diagnosed according to the ADA guidelines. The prevalence of diabetes was similar in the nonsecreting patients and in the intermediate minor phenotype patients $(15.2 \%$ and $18.3 \%)$, whereas it was higher in the intermediate major phenotype patients $(32.7 \%)$, and even higher in the SCS patients $(42.1 \%)(P=0.004)$. Looking at these data it is possible to speculate that increasing patterns of subclinical hypercortisolism could indeed lead to alterations in the glucose metabolism; moreover, the prevalence of diabetes seems to increase according to the severity of the subclinical hypercortisolism. In this study we also showed an independent relationship between T2D and the SCS secreting pattern (with an independent contribution of age, which was higher in the SCS patients with respect to the nonsecreting patients). These data lead to the conclusion that the subclinical alterations of the HPA axis should be considered as a risk factor for diabetes. Although the causeeffects relationship between SCS and diabetes has still to be clarified, the beneficial effects of surgical treatment of SCS in order to improve or cure this disease are yet to be determined. Many studies reported an improvement of T2D after adrenalectomy: a prospective randomized study conducted on 45 SCS patients who were randomly selected for surgery or medical treatment showed an improvement of the T2D in $62.5 \%$ of patients after a mean followup of 8 years [119]. On the other hand, some studies did not confirm these findings [120]. However, many prospective studies have some biases, mainly related to the selection criteria for surgery, which lead to difficulties in interpreting the data and consequently in evaluating the efficacy of adrenalectomy in SCS patients with diabetes: patients undergoing adrenalectomy generally have an adrenal mass size $>4 \mathrm{~cm}$ of diameter, or they have clinical complications of diabetes (such as high glycated haemoglobin, nephropathy, etc.) which are expected to improve after surgery. Large prospective and randomized studies are needed to evaluate the adequate treatment for SCS patients with diabetes.

\section{Summary and Conclusions}

Glucocorticoids exert deleterious effects on the glucose metabolism, leading to a wide range of alterations, from insulin-resistance to overt and complicated diabetes. The complex net of mechanisms that link hypercortisolism (endogenous or exogenous) to the development of these abnormalities is only partially understood. Understanding 
the mechanisms of glucocorticoid-induced glucose alterations could lead to the development of novel therapeutic anti-inflammatory drugs, with reduced impact on glucose metabolism. Finally, the link between hypercortisolism and metabolic syndrome deserves more interest: unravelling the open questions in this field could lead to a significant improvement in the treatment of obesity, diabetes, and its complications.

\section{References}

[1] M. Stumvoll, B. J. Goldstein, and T. W. van Haeften, “Type 2 diabetes: principles of pathogenesis and therapy," The Lancet, vol. 365, no. 9467, pp. 1333-1346, 2005.

[2] G. M. Reaven, "Role of insulin resistance in human disease," Diabetes, vol. 37, no. 12, pp. 1595-1607, 1988.

[3] S. E. Kahn, R. L. Hull, and K. M. Utzschneider, "Mechanisms linking obesity to insulin resistance and type 2 diabetes," Nature, vol. 444, no. 7121, pp. 840-846, 2006.

[4] R. Burcelin, C. Knauf, and P. D. Cani, "Pancreatic $\alpha$-cell dysfunction in diabetes," Diabetes and Metabolism, vol. 34, supplement 2, pp. S49-S55, 2008.

[5] H. Mulder, C. L. F. Nagorny, V. Lyssenko, and L. Groop, "Melatonin receptors in pancreatic islets: good morning to a novel type 2 diabetes gene," Diabetologia, vol. 52, no. 7, pp. 1240-1249, 2009.

[6] M. S. Cooper and P. M. Stewart, " $11 \beta$-hydroxysteroid dehydrogenase type 1 and its role in the hypothalamuspituitary-adrenal axis, metabolic syndrome, and inflammation," Journal of Clinical Endocrinology and Metabolism, vol. 94, no. 12, pp. 4645-4654, 2009.

[7] D. J. Drucker and M. A. Nauck, "The incretin system: glucagon-like peptide-1 receptor agonists and dipeptidyl peptidase- 4 inhibitors in type 2 diabetes," The Lancet, vol. 368, no. 9548, pp. 1696-1705, 2006.

[8] M. Boscaro, L. Barzon, F. Fallo, and N. Sonino, "Cushing's syndrome," The Lancet, vol. 357, no. 9258, pp. 783-791, 2001.

[9] J. M. Connell, J. A. Whitworth, D. L. Davies, A. F. Lever, A. M. Richards, and R. Fraser, "Effects of ACTH and cortisol administration on blood pressure, electrolyte metabolism, atrial natriuretic peptide and renal function in normal man," Journal of Hypertension, vol. 5, no. 4, pp. 425-433, 1987.

[10] P. Björntorp, G. Holm, and R. Rosmond, "Hypothalamic arousal, insulin resistance and type 2 diabetes mellitus," Diabetic Medicine, vol. 16, no. 5, pp. 373-383, 1999.

[11] E. Charmandari, G. P. Chrousos, G. I. Lambrou et al., "Peripheral CLOCK regulates target-tissue glucocorticoid receptor transcriptional activity in a circadian fashion in man," PLoS ONE, vol. 6, no. 9, Article ID e25612, 2011.

[12] J. W. Funder, "Glucocorticoid and mineralcorticoid receptors: biology and clinical relevance," Annual Review of Medicine, vol. 48, pp. 231-240, 1997.

[13] C. M. Bamberger, H. M. Schulte, and G. P. Chrousos, "Molecular determinants of glucocorticoid receptor function and tissue sensitivity to glucocorticoids," Endocrine Reviews, vol. 17, no. 3, pp. 245-261, 1996.

[14] R. H. DeRijk, M. Schaaf, and E. R. de Kloet, "Glucocorticoid receptor variants: clinical implications," Journal of Steroid Biochemistry and Molecular Biology, vol. 81, no. 2, pp. 103122, 2002.

[15] J. R. Seckl, "11 $\beta$-hydroxysteroid dehydrogenases: changing glucocorticoid action," Current Opinion in Pharmacology, vol. 4, no. 6, pp. 597-602, 2004.
[16] G. Arnaldi, A. Angeli, A. B. Atkinson et al., "Diagnosis and complications of Cushing's syndrome: a consensus statement," Journal of Clinical Endocrinology and Metabolism, vol. 88, no. 12, pp. 5593-5602, 2003.

[17] M. J. Barahona, N. Sucunza, E. Resmini et al., "Deleterious effects of glucocorticoid replacement on bone in women after long-term remission of Cushing's syndrome," Journal of Bone and Mineral Research, vol. 24, no. 11, pp. 1841-1846, 2009.

[18] A. Colao, R. Pivonello, S. Spiezia et al., "Persistence of increased cardiovascular risk in patients with Cushing's disease after five years of successful cure," Journal of Clinical Endocrinology and Metabolism, vol. 84, no. 8, pp. 2664-2672, 1999.

[19] C. di Somma, R. Pivonello, S. Loche et al., "Severe impairment of bone mass and turnover in Cushing's disease: comparison between childhood-onset and adulthood-onset disease," Clinical Endocrinology, vol. 56, no. 2, pp. 153-158, 2002.

[20] L. D. Dorn, E. S. Burgess, T. C. Friedman, B. Dubbert, P. W. Gold, and G. P. Chrousos, "The longitudinal course of psychopathology in Cushing's syndrome after correction of hypercortisolism," Journal of Clinical Endocrinology and Metabolism, vol. 82, no. 3, pp. 912-919, 1997.

[21] M. Minetto, G. Reimondo, G. Osella, M. Ventura, A. Angeli, and M. Terzolo, "Bone loss is more severe in primary adrenal than in pituitary-dependent Cushing's syndrome," Osteoporosis International, vol. 15, no. 11, pp. 855-861, 2004.

[22] J. Newell-Price, X. Bertagna, A. B. Grossman, and L. K. Nieman, "Cushing's syndrome," The Lancet, vol. 367, no. 9522, pp. 1605-1617, 2006.

[23] F. P. Giraldi, M. Moro, and F. Cavagnini, "Gender-related differences in the presentation and course of Cushing's disease," Journal of Clinical Endocrinology and Metabolism, vol. 88, no. 4, pp. 1554-1558, 2003.

[24] R. Pivonello, M. C. de Martino, M. de Leo, G. Lombardi, and A. Colao, "Cushing's syndrome," Endocrinology and Metabolism Clinics of North America, vol. 37, no. 1, pp. 135149, 2008.

[25] N. Sonino, G. A. Fava, A. R. Raffi, M. Boscaro, and F. Fallo, "Clinical correlates of major depression in Cushing's disease," Psychopathology, vol. 31, no. 6, pp. 302-306, 1998.

[26] N. Sonino and G. A. Fava, "Psychiatric disorders associated with Cushing's syndrome: epidemiology, pathophysiology and treatment," CNS Drugs, vol. 15, no. 5, pp. 361-373, 2001.

[27] T. Mancini, B. Kola, F. Mantero, M. Boscaro, and G. Arnaldi, "High cardiovascular risk in patients with Cushing's syndrome according to 1999 WHO/ISH guidelines," Clinical Endocrinology, vol. 61, no. 6, pp. 768-777, 2004.

[28] R. N. Clayton, D. Raskauskiene, R. C. Reulen, and P. W. Jones, "Mortality and morbidity in Cushing's disease over 50 Years in Stoke-on-Trent, UK: audit and meta-analysis of literature," Journal of Clinical Endocrinology and Metabolism, vol. 96, no. 3, pp. 632-642, 2011.

[29] J. Etxabe and J. A. Vazquez, "Morbidity and mortality in Cushing's disease: an epidemiological approach," Clinical Endocrinology, vol. 40, no. 4, pp. 479-484, 1994.

[30] G. D. Hammer, J. B. Tyrrell, K. R. Lamborn et al., "Transsphenoidal microsurgery for Cushing's disease: Initial outcome and long-term results," Journal of Clinical Endocrinology and Metabolism, vol. 89, no. 12, pp. 6348-6357, 2004.

[31] O. M. Dekkers, N. R. Biermasz, A. M. Pereira et al., "Mortality in patients treated for Cushing's disease is increased, compared with patients treated for non-functioning pituitary 
macroadenomas," Journal of Clinical Endocrinology and Metabolism, vol. 92, pp. 976-981, 2007.

[32] J. Lindholm, S. Juul, J. O. L. Jørgensen et al., "Incidence and late prognosis of Cushing's syndrome: a population-based study," Journal of Clinical Endocrinology and Metabolism, vol. 86, no. 1, pp. 117-123, 2001.

[33] M. J. Bolland, I. M. Holdaway, J. E. Berkeley et al., "Mortality and morbidity in Cushing's syndrome in New Zealand," Clinical Endocrinology, vol. 75, no. 4, pp. 436-442, 2011.

[34] D. H. van Raalte, D. M. Ouwens, and M. Diamant, "Novel insights into glucocorticoid-mediated diabetogenic effects: towards expansion of therapeutic options?" European Journal of Clinical Investigation, vol. 39, no. 2, pp. 81-93, 2009.

[35] S. Seino, T. Shibasaki, and K. Minami, "Pancreatic $\beta$-cell signalling: toward better understanding of diabetes and its treatment," Proceedings of the Japan Academy, Series B, vol. 86, no. 6, pp. 563-577, 2010.

[36] K. B. Hansen, T. Vilsbøll, J. I. Bagger, J. J. Holst, and F. K. Knop, "Reduced glucose tolerance and insulin resistance induced by steroid treatment, relative physical inactivity, and high-calorie diet impairs the incretin effect in healthy subjects," Journal of Clinical Endocrinology and Metabolism, vol. 95, no. 7, pp. 3309-3317, 2010.

[37] R. Pivonello, M. de Leo, P. Vitale et al., "Pathophysiology of diabetes mellitus in Cushing's syndrome," Neuroendocrinology, vol. 92, supplement 1, pp. 77-81, 2010.

[38] H. Cassuto, K. Kochan, K. Chakravarty et al., "Glucocorticoids regulate transcription of the gene for phosphoenolpyruvate carboxykinase in the liver via an extended glucocorticoid regulatory unit," The Journal of Biological Chemistry, vol. 280, no. 40, pp. 33873-33884, 2005.

[39] R. Patel, M. Patel, R. Tsai et al., "LXRb is required for glucocorticoid-induced hyperglycemia and hepatosteatosis in mice," Journal of Clinical Investigation, vol. 121, no. 1, pp. 431-441, 2011.

[40] C. M. Rondinone, "Adipocyte-derived hormones, cytokines, and mediators," Endocrine, vol. 29, no. 1, pp. 81-90, 2006.

[41] I. Castan-Laurell, C. Dray, C. Attané, T. Duparc, C. Knauf, and P. Valet, "Apelin, diabetes, and obesity," Endocrine, vol. 40, no. 1, pp. 1-9, 2011.

[42] R. A. Feelders, S. J. Pulgar, A. Kempel, and A. M. Pereira, "The burden of Cushing's disease (CD): clinical and health-related quality of life aspects," European Journal of Endocrinology, vol. 167, no. 3, pp. 311-326, 2012.

[43] K. Mullan, N. Black, A. Thiraviaraj et al., "Is there value in routine screening for Cushing's syndrome in patients with diabetes?" Journal of Clinical Endocrinology and Metabolism, vol. 95, no. 5, pp. 2262-2265, 2010.

[44] T. Krarup, T. Krarup, and C. Hagen, "Do patients with type 2 diabetes mellitus have an increased prevalence of Cushing's syndrome?" Diabetes/Metabolism Research and Reviews, vol. 28, no. 3, pp. 219-227, 2012.

[45] M. G. Burt, G. W. Roberts, N. R. Aguilar-Loza, P. Frith, and S. N. Stranks, "Continuous monitoring of circadian glycemic patterns in patients receiving prednisolone for COPD," Journal of Clinical Endocrinology and Metabolism, vol. 96, no. 6, pp. 1789-1796, 2011.

[46] World Health Organization, Definition and Diagnosis of Diabetes Mellitus and Intermediate Hyperglycemia: Report of a WHO/IDF Consultation, World Health Organization, Geneva, Switzerland, 2006.

[47] American Diabetes Association, "Diagnosis and classification of diabetes mellitus," Diabetes Care, vol. 34, supplement 1, pp. S62-S69, 2011.
[48] D. R. Matthews, J. P. Hosker, A. S. Rudenski, B. A. Naylor, D. F. Treacher, and R. C. Turner, "Homeostasis model assessment: insulin resistance and $\beta$-cell function from fasting plasma glucose and insulin concentrations in man," Diabetologia, vol. 28, no. 7, pp. 412-419, 1985.

[49] M. C. Lansang and L. K. Hustak, "Glucocorticoid-induced diabetes and adrenal suppression: how to detect and manage them," Cleveland Clinic Journal of Medicine, vol. 78, no. 11, pp. 748-756, 2011.

[50] J. N. Clore and L. Thurby-Hay, "Glucocorticoid-induced hyperglycemia," Endocrine Practice, vol. 15, no. 5, pp. 469474, 2009.

[51] S. Panthakalam, D. Bhatnagar, and P. Klimiuk, "The prevalence and management of hyperglycaemia in patients with rheumatoid arthritis on corticosteroid therapy," Scottish Medical Journal, vol. 49, no. 4, pp. 139-141, 2004.

[52] T. Uzu, T. Harada, M. Sakaguchi et al., "Glucocorticoidinduced diabetes mellitus: prevalence and risk factors in primary renal diseases," Nephron-Clinical Practice, vol. 105, no. 2, pp. c54-c57, 2007.

[53] J. H. Gurwitz, R. L. Bohn, R. J. Glynn, M. Monane, H. Mogun, and J. Avorn, "Glucocorticoids and the risk for initiation of hypoglycemic therapy," Archives of Internal Medicine, vol. 154, no. 1, pp. 97-101, 1994.

[54] J. Davidson, A. Wilkinson, J. Dantal et al., "New-onset diabetes after transplantation: 2003 international consensus guidelines-proceedings of an international expert panel meeting Barcelona, Spain 19 February 2003," Transplantation, vol. 75, no. 10, pp. SS1-SS24, 2003.

[55] G. Pagano, P. Cavallo Perin, M. Cassader et al., "An in vivo and in vitro study of the mechanism of prednisone-induced insulin resistance in healthy subjects," Journal of Clinical Investigation, vol. 72, no. 5, pp. 1814-1820, 1983.

[56] D. Abdelmannan, R. Tahboub, S. Genuth et al., "Effect of dexamethasone on oral glucose tolerance in normal individuals," Endocrine Practice, vol. 16, no. 5, pp. 770-777, 2010.

[57] N. Nicod, V. Giusti, C. Besse, and L. Tappy, "Metabolic adaptations to dexamethasone-induced insulin resistance in healthy volunteers," Obesity Research, vol. 11, no. 5, pp. 625631, 2003.

[58] P. H. Dessein and B. I. Joffe, "Insulin resistance and impaired beta cell function in rheumatoid arthritis," Arthritis and Rheumatism, vol. 54, no. 9, pp. 2765-2775, 2006.

[59] S. Gremlich, R. Roduit, and B. Thorens, "Dexamethasone induces posttranslational degradation of GLUT2 and inhibition of insulin secretion in isolated pancreatic $\beta$ cells. Comparison with the effects of fatty acids," The Journal of Biological Chemistry, vol. 272, no. 6, pp. 3216-3222, 1997.

[60] A. Khan, C. G. Ostenson, P. O. Berggren, and S. Efendic, "Glucocorticoid increases glucose cycling and inhibits insulin release in pancreatic islets of ob/ob mice," American Journal of Physiology, vol. 263, no. 4, pp. E663-E666, 1992.

[61] S. Ullrich, S. Berchtold, F. Ranta et al., "Serum- and glucocorticoid-inducible kinase 1 (SGK1) mediates glucocorticoidinduced inhibition of insulin secretion," Diabetes, vol. 54, no. 4, pp. 1090-1099, 2005.

[62] J. I. Cleeman, "Executive summary of the third report of the national cholesterol education program (NCEP) expert panel on detection, evaluation, and treatment of high blood cholesterol in adults (adult treatment panel III)," The Journal of the American Medical Association, vol. 285, no. 19, pp. 2486-2497, 2001.

[63] Z. T. Bloomgarden, "American association of clinical endocrinologists (AACE) consensus conference on the insulin 
resistance syndrome: 25-26 August 2002, Washington, DC," Diabetes Care, vol. 26, no. 4, pp. 1297-1303, 2003.

[64] B. Balkau and M. A. Charles, "Comment on the provisional report from the WHO consultation. European group for the study of insulin resistance (EGIR)," Diabetic Medicine, vol. 16, no. 5, pp. 442-443, 1999.

[65] S. M. Grundy, J. I. Cleeman, S. R. Daniels et al., "Diagnosis and management of the metabolic syndrome: an American heart association/national heart, lung, and blood institute scientific statement," Circulation, vol. 112, no. 17, pp. 27352752, 2005.

[66] P. Mårin, N. Darin, T. Amemiya, B. Andersson, S. Jern, and P. Bjorntorp, "Cortisol secretion in relation to body fat distribution in obese premenopausal women," Metabolism, vol. 41, no. 8, pp. 882-886, 1992.

[67] R. S. Gill, A. M. Sharma, S. S. Gill, D. W. Birch, and S. Karmali, "The impact of obesity on diabetes mellitus and the role of bariatric surgery," Maturitas, vol. 69, no. 2, pp. 137$140,2011$.

[68] D. M. Lloyd-Jones, K. Liu, L. A. Colangelo et al., "Consistently stable or decreased body mass index in young adulthood and longitudinal changes in metabolic syndrome components: the coronary artery risk development in young adults study," Circulation, vol. 115, no. 8, pp. 1004-1011, 2007.

[69] G. A. Colditz, W. C. Willett, A. Rotnitzky, and J. E. Manson, "Weight gain as a risk factor for clinical diabetes mellitus in women," Annals of Internal Medicine, vol. 122, no. 7, pp. 481486, 1995.

[70] R. R. Wing, C. H. Bunker, L. H. Kuller, and K. A. Matthews, "Insulin, body mass index, and cardiovascular risk factors in premenopausal women," Arteriosclerosis, vol. 9, no. 4, pp. 479-484, 1989.

[71] J. M. Chan, E. B. Rimm, G. A. Colditz, M. J. Stampfer, and W. C. Willett, "Obesity, fat distribution, and weight gain as risk factors for clinical diabetes in men," Diabetes Care, vol. 17, no. 9, pp. 961-969, 1994.

[72] A. Schienkiewitz, M. B. Schulze, K. Hoffmann, A. Kroke, and H. Boeing, "Body mass index history and risk of type 2 diabetes: results from the European prospective investigation into cancer and nutrition (EPIC)-potsdam study," American Journal of Clinical Nutrition, vol. 84, no. 2, pp. 427-433, 2006.

[73] S. S. Cohen, L. B. Signorello, and W. J. Blot, "Adult weight gain and diabetes among African American and White adults in southeastern US communities," Preventive Medicine, vol. 49, no. 6, pp. 476-481, 2009.

[74] N. T. Nguyen, C. P. Magno, K. T. Lane, M. W. Hinojosa, and J. S. Lane, "Association of hypertension, diabetes, dyslipidemia, and metabolic syndrome with obesity: findings from the national health and nutrition examination survey, 1999 to 2004," Journal of the American College of Surgeons, vol. 207, no. 6, pp. 928-934, 2008.

[75] O. R. Moon, N. S. Kim, S. M. Jang, T. H. Yoon, and S. O. Kim, "The relationship between body mass index and the prevalence of obesity-related diseases based on the 1995 national health interview survey in Korea," Obesity Reviews, vol. 3, no. 3, pp. 191-196, 2002.

[76] M. Rebuffé-Scrive, M. Krotkiewski, J. Elfverson, and P. Bjorntorp, "Muscle and adipose tissue morphology and metabolism in Cushing's syndrome," Journal of Clinical Endocrinology and Metabolism, vol. 67, no. 6, pp. 1122-1128, 1988.

[77] M. J. Weigensberg, C. M. Toledo-Corral, and M. I. Goran, "Association between the metabolic syndrome and serum cortisol in overweight Latino youth," Journal of Clinical
Endocrinology and Metabolism, vol. 93, no. 4, pp. 1372-1378, 2008.

[78] R. Pasquali, S. Cantobelli, F. Casimirri et al., "The hypothalamic-pituitary-adrenal axis in obese women with different patterns of body fat distribution," Journal of Clinical Endocrinology and Metabolism, vol. 77, no. 2, pp. 341-346, 1993.

[79] M. Duclos, P. M. Pereira, P. Barat, B. Gatta, and P. Roger, "Increased cortisol unavailability, abdominal obesity, and the metabolic syndrome in obese women," Obesity Research, vol. 13, no. 7, pp. 1157-1166, 2005.

[80] M. Rebuffé-Scrive, U. A. Walsh, B. McEwen, and J. Rodin, "Effect of chronic stress and exogenous glucocorticoids on regional fat distribution and metabolism," Physiology and Behavior, vol. 52, no. 3, pp. 583-590, 1992.

[81] E. S. Epel, B. McEwen, T. Seeman et al., "Stress and body shape: stress-induced cortisol secretion is consistently greater among women with central fat," Psychosomatic Medicine, vol. 62, no. 5, pp. 623-632, 2000.

[82] J. Marniemi, E. Kronholm, S. Aunola et al., "Visceral fat and psychosocial stress in identical twins discordant for obesity," Journal of Internal Medicine, vol. 251, no. 1, pp. 35-43, 2002.

[83] R. Pasquali and V. Vicennati, "Activity of the hypothalamicpituitary-adrenal axis in different obesity phenotypes," International Journal of Obesity, vol. 24, no. 2, pp. S47-S49, 2000.

[84] E. S. Epel, B. McEwen, T. Seeman et al., "Stress and body shape: Stress-induced cortisol secretion is consistently greater among women with central fat," Psychosomatic Medicine, vol. 62, no. 5, pp. 623-632, 2000.

[85] M. Korbonits, P. J. Trainer, M. L. Nelson et al., "Differential stimulation of cortisol and dehydroepiandrosterone levels by food in obese and normal subjects: relation to body fat distribution," Clinical Endocrinology, vol. 45, no. 6, pp. 699706, 1996.

[86] V. Vicennati, L. Ceroni, L. Gagliardi, A. Gambineri, and R. Pasquali, "Response of the hypothalamic pituitary-adrenocortical axis to high-protein/fat and high-carbohydrate meals in women with different obesity phenotypes," Journal of Clinical Endocrinology and Metabolism, vol. 87, no. 8, pp. 3984-3988, 2002.

[87] M. Duclos, B. Gatta, J. B. Corcuff, M. Rashedi, F. Pehourcq, and P. Roger, "Fat distribution in obese women is associated with subtle alterations of the hypothalamic-pituitary-adrenal axis activity and sensitivity to glucocorticoids," Clinical Endocrinology, vol. 55, no. 4, pp. 447-454, 2001.

[88] R. Pasquali, B. Anconetani, R. Chattat et al., "Hypothalamicpituitary-adrenal axis activity and its relationship to the autonomic nervous system in women with visceral and subcutaneous obesity: effects of the corticotropin-releasing factor/arginine-vasopressin test and of stress," Metabolism, vol. 45, no. 3, pp. 351-356, 1996.

[89] R. Pasquali and V. Vicennati, "The abdominal obesity phenotype and insulin resistance are associated with abnormalities of the hypothalamic-pituitary-adrenal axis in humans," Hormone and Metabolic Research, vol. 32, no. 11-12, pp. 521525, 2000.

[90] R. Pasquali, B. Ambrosi, D. Armanini et al., "Cortisol and ACTH response to oral dexamethasone in obesity and effects of sex, body fat distribution, and dexamethasone concentrations: a dose-response study," Journal of Clinical Endocrinology and Metabolism, vol. 87, no. 1, pp. 166-175, 2002.

[91] R. Rosmond, M. F. Dallman, and P. Björntorp, "Stress-related cortisol secretion in men: relationships with abdominal 
obesity and endocrine, metabolic and hemodynamic abnormalities," Journal of Clinical Endocrinology and Metabolism, vol. 83, no. 6, pp. 1853-1859, 1998.

[92] V. Vicennati, F. Pasqui, C. Cavazza et al., "Cortisol, energy intake, and food frequency in overweight/obese women," Nutrition, vol. 27, no. 6, pp. 677-680, 2011.

[93] P. Anagnostis, N. Katsiki, F. Adamidou et al., " $11 \beta$ Hydroxysteroid dehydrogenase type 1 inhibitors: novel agents for the treatment of metabolic syndrome and obesityrelated disorders?" Metabolism. In press.

[94] Y. Isomura, T. Mune, H. Morita et al., "Physiologic roles of $11 \beta$-hydroxysteroid dehydrogenase type 2 in kidney," Metabolism, vol. 55, no. 10, pp. 1352-1357, 2006.

[95] B. Walker and R. Andrew, "Tissue production of cortisol by 11betahydroxysteroid dehydrogenase type 1 and metabolic disease," Annals of the New York Academy of Sciences, vol. 1083, pp. 165-184, 2006.

[96] H. Masuzaki, J. Paterson, H. Shinyama et al., "A transgenic model of visceral obesity and the metabolic syndrome," Science, vol. 294, no. 5549, pp. 2166-2170, 2001.

[97] M. Wamil and J. R. Seckl, "Inhibition of $11 \beta$-hydroxysteroid dehydrogenase type 1 as a promising therapeutic target," Drug Discovery Today, vol. 12, no. 13-14, pp. 504-520, 2007.

[98] H. Masuzaki, H. Yamamoto, C. J. Kenyon et al., "Transgenic amplification of glucocorticoid action in adipose tissue causes high blood pressure in mice," Journal of Clinical Investigation, vol. 112, no. 1, pp. 83-90, 2003.

[99] J. Rosenstock, S. Banarer, V. A. Fonseca et al., "The 11- $\beta$ hydroxysteroid dehydrogenase type 1 inhibitor INCB13739 improves hyperglycemia in patients with type 2 diabetes inadequately controlled by metformin monotherapy," Diabetes Care, vol. 33, no. 7, pp. 1516-1522, 2010.

[100] P. Stewart, “Tissue-specific Cushing's syndrome uncovers a new target in treating the metabolic syndrome-11 $\beta$ hydroxysteroid dehydrogenase type 1 ," Clinical Medicine, vol. 5, pp. 142-146, 2005.

[101] I. Bujalska, S. Kumar, and P. Stewart, "Does central obesity reflect "Cushing's disease of the omentum"?" The Lancet, vol. 349, no. 9060, pp. 1210-1213, 1997.

[102] A. A. Tahrani, C. J. Bailey, S. Del Prato, and A. H. Barnett, "Management of type 2 diabetes: new and future developments in treatment," The Lancet, vol. 378, no. 9786, pp. 182197, 2011.

[103] P. U. Feig, S. Shah, A. Hermanowski-Vosatka et al., "Effects of an $11 \beta$-hydroxysteroid dehydrogenase type 1 inhibitor, MK0916, in patients with type 2 diabetes mellitus and metabolic syndrome," Diabetes, Obesity and Metabolism, vol. 13, no. 6, pp. 498-504, 2011.

[104] S. Shah, A. Hermanowski-Vosatka, K. Gibson et al., "Efficacy and safety of the selective $11 \beta$-HSD-1 inhibitors MK-0736 and MK-0916 in overweight and obese patients with hypertension," Journal of the American Society of Hypertension, vol. 5, no. 3, pp. 166-176, 2011.

[105] J. P. Gibbs, M. G. Emery, I. McCaffery et al., "Population pharmacokinetic/pharmacodynamic model of subcutaneous adipose $11 \beta$-hydroxysteroid dehydrogenase type 1 (11 $\beta$ HSD1) activity after oral administration of AMG 221, a selective $11 \beta$-HSD1 Inhibitor," Journal of Clinical Pharmacology, vol. 51, no. 6, pp. 830-841, 2011.

[106] G. P. Chrousos, "Is $11 \beta$-hydroxysteroid dehydrogenase type 1 a good therapeutic target for blockade of glucocorticoid actions?" Proceedings of the National Academy of Sciences of the United States of America, vol. 101, no. 17, pp. 6329-6330, 2004.
[107] "NIH state-of-the-science statement on management of the clinically inapparent adrenal mass ("incidentaloma")," NIH Consensus and State-of-the-Science Statements, vol. 19, no. 2, pp. 1-25, 2002.

[108] M. Reincke, “Subclinical Cushing's syndrome," Endocrinology and Metabolism Clinics of North America, vol. 29, no. 1, pp. 43-56, 2000.

[109] F. Mantero, M. Terzolo, G. Arnaldi et al., "A survey on adrenal incidentaloma in Italy," Journal of Clinical Endocrinology and Metabolism, vol. 85, no. 2, pp. 637-644, 2000.

[110] M. Terzolo, A. Pia, A. Alì et al., "Adrenal incidentaloma: a new cause of the metabolic syndrome?" Journal of Clinical Endocrinology and Metabolism, vol. 87, no. 3, pp. 998-1003, 2002.

[111] R. Giordano, F. Guaraldi, R. Berardelli et al., "Glucose metabolism in patients with subclinical Cushing's syndrome," Endocrine, vol. 41, no. 3, pp. 415-423, 2012.

[112] T. L. Mazzuco, I. Bourdeau, and A. Lacroix, "Adrenal incidentalomas and subclinical Cushing's syndrome: diagnosis and treatment," Current Opinion in Endocrinology, Diabetes and Obesity, vol. 16, no. 3, pp. 203-210, 2009.

[113] V. Morelli, B. Masserini, A. S. Salcuni et al., "Subclinical hypercortisolism: correlation between biochemical diagnostic criteria and clinical aspects," Clinical Endocrinology, vol. 73, no. 2, pp. 161-166, 2010.

[114] R. Rossi, L. Tauchmanova, A. Luciano et al., "Subclinical Cushing's syndrome in patients with adrenal incidentaloma: clinical and biochemical features," Journal of Clinical Endocrinology and Metabolism, vol. 85, no. 4, pp. 1440-1448, 2000.

[115] M. Terzolo, S. Bovio, A. Pia et al., "Midnight serum cortisol as a marker of increased cardiovascular risk in patients with a clinically inapparent adrenal adenoma," European Journal of Endocrinology, vol. 153, no. 2, pp. 307-315, 2005.

[116] L. Tauchmanovà, R. Rossi, B. Biondi et al., "Patients with subclinical Cushing's syndrome due to adrenal adenoma have increased cardiovascular risk," Journal of Clinical Endocrinology and Metabolism, vol. 87, no. 11, pp. 4872-4878, 2002.

[117] M. Terzolo, S. Bovio, G. Reimondo et al., "Subclinical Cushing's syndrome in adrenal incidentalomas," Endocrinology and Metabolism Clinics of North America, vol. 34, no. 2, pp. 423-439, 2005.

[118] G. Di Dalmazi, V. Vicennati, E. Rinaldi et al., "Progressively increased patterns of subclinical cortisol hypersecretion in adrenal incidentalomas differently predict major metabolic and cardiovascular outcomes: a large cross-sectional study," European Journal of Endocrinology, vol. 166, pp. 669-677, 2012.

[119] A. Toniato, I. Merante-Boschin, G. Opocher, M. R. Pelizzo, F. Schiavi, and E. Ballotta, "Surgical versus conservative management for subclinical cushing syndrome in adrenal incidentalomas: a prospective randomized study," Annals of Surgery, vol. 249, no. 3, pp. 388-391, 2009.

[120] R. Giordano, E. Marinazzo, R. Berardelli et al., "Long-term morphological, hormonal, and clinical follow-up in a single unit on 118 patients with adrenal incidentalomas," European Journal of Endocrinology, vol. 162, no. 4, pp. 779-785, 2010. 


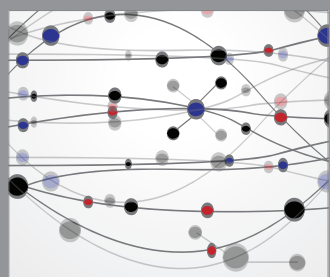

The Scientific World Journal
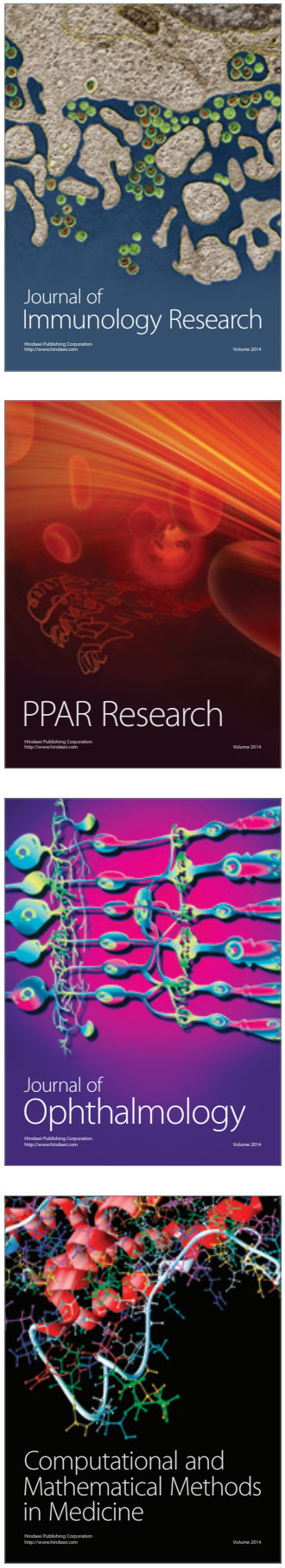

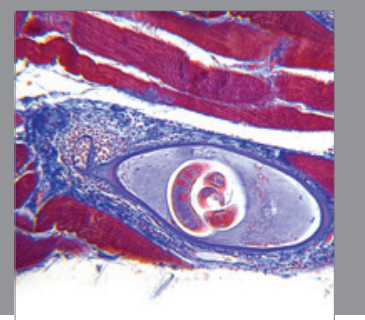

Gastroenterology

Research and Practice
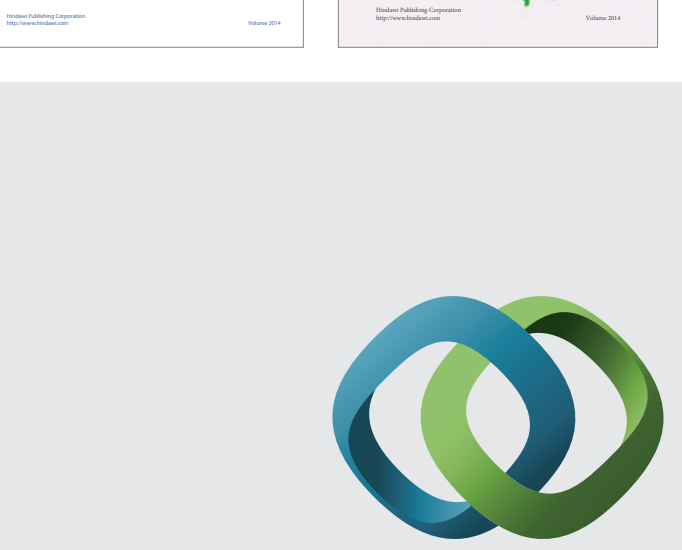

\section{Hindawi}

Submit your manuscripts at

http://www.hindawi.com
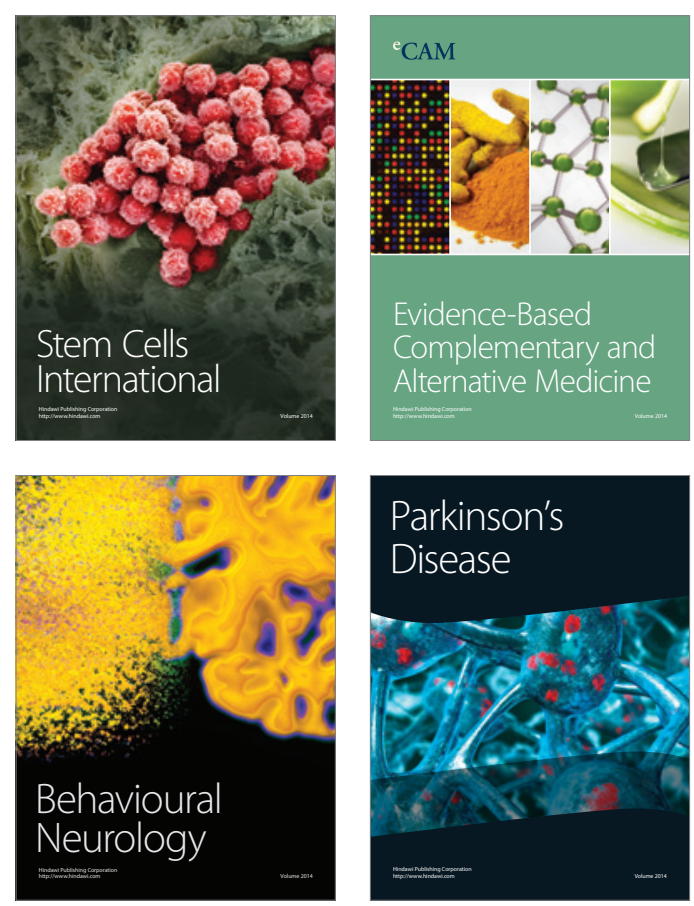

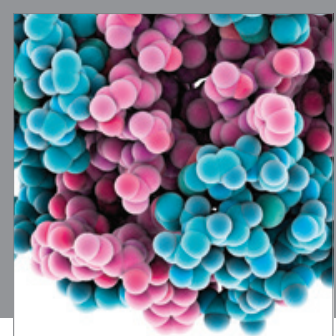

Journal of
Diabetes Research

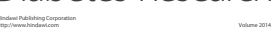

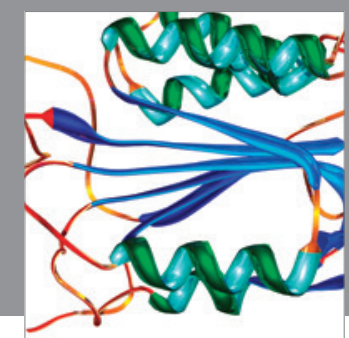

Disease Markers
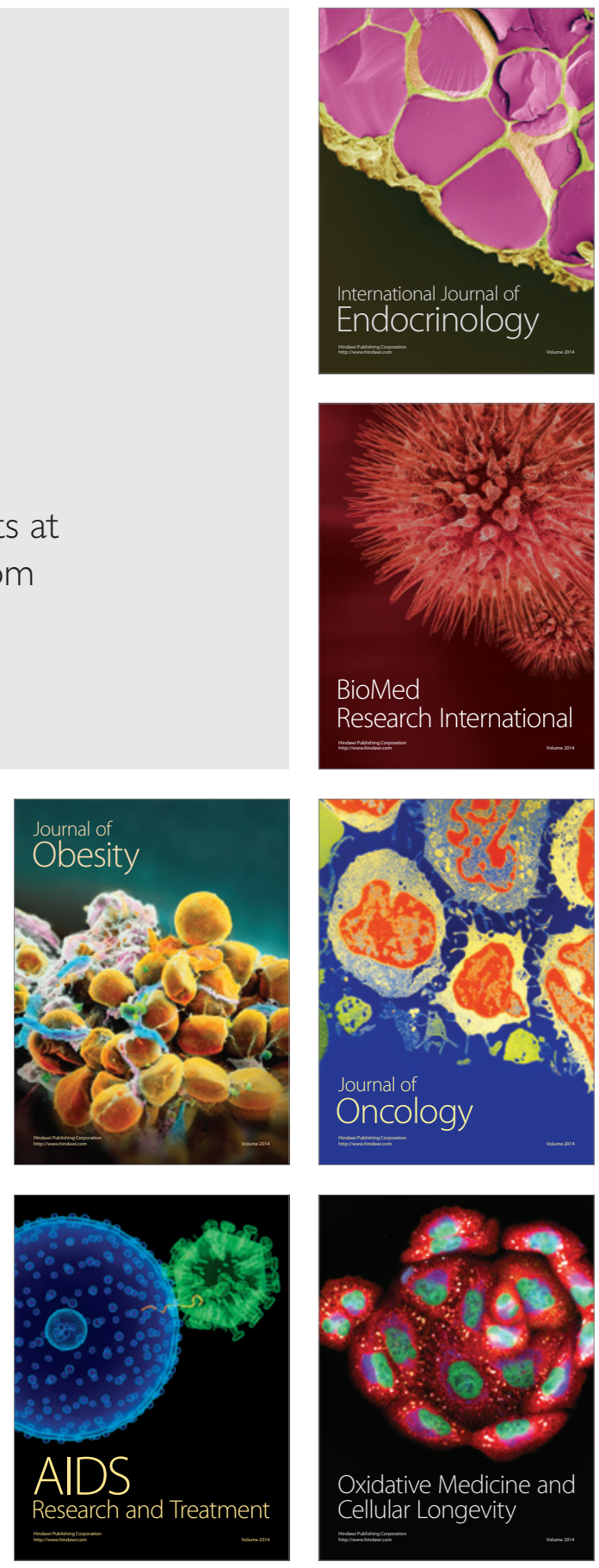